\title{
Curcumin eliminates the effect of advanced glycation end-products (AGEs) on the divergent regulation of gene expression of receptors of AGEs by interrupting leptin signaling
}

\author{
Youcai Tang and Anping Chen
}

\begin{abstract}
Non-alcoholic steatohepatitis (NASH) is a major risk factor for hepatic fibrogenesis. NASH is often found in diabetic patients with hyperglycemia. Hyperglycemia induces non-enzymatic glycation of proteins, yielding advanced glycation end-products (AGEs). Effects of AGEs are mainly mediated by two categories of cytoplasmic membrane receptors.

Receptor for AGEs (RAGE) is associated with increased oxidative stress and inflammation, whereas AGE receptor-1 (AGE-R1) is involved in detoxification and clearance of AGEs. Activation of hepatic stellate cells (HSC) is crucial to the development of hepatic fibrosis. We recently reported that AGEs stimulated HSC activation likely by inhibiting gene expression of AGER1 and inducing gene expression of RAGE in HSC, which were eliminated by the antioxidant curcumin. This study is to test our hypothesis that curcumin eliminates the effects of AGEs on the divergent regulation of the two receptors of AGEs in HSC by interrupting the AGE-caused activation of leptin signaling, leading to the inhibition of HSC activation. We observed herein that AGEs activated leptin signaling by inducing gene expression of leptin and its receptor in HSC. Like AGEs, leptin differentially regulated gene expression of RAGE and AGE-R1. Curcumin eliminated the effects of AGEs in HSC by interrupting leptin signaling and activating transcription factor NF-E2 p45-related factor 2 (Nrf2), leading to the elevation of cellular glutathione and the attenuation of oxidative stress. In conclusions, curcumin eliminated the effects of AGEs on the divergent regulation of gene expression of RAGE and AGE-R1 in HSC by interrupting the AGE-caused activation of leptin signaling, leading to the inhibition of HSC activation.
\end{abstract}

Laboratory Investigation (2014) 94, 503-516; doi:10.1038/labinvest.2014.42; published online 10 March 2014

KEYWORDS: advanced glycation end-products; glutathione; hepatic fibrosis; hepatic stellate cells; oxidant stress

Non-alcoholic steatohepatitis (NASH) is a major risk factor for the development of hepatic fibrosis. ${ }^{1}$ Major liver-related clinical consequences are minimized in NASH patients if fibrogenesis can be halted. ${ }^{2,3}$ NASH is often found in obese and diabetic patients with hyperglycemia. ${ }^{4}$ Hyperglycemia induces non-enzymatic glycation of proteins, yielding advanced glycation end-products (AGEs), ${ }^{5}$ which are accelerated by oxidative stress. ${ }^{6}$ The liver is not only a site for clearing circulating AGEs, but also a target organ. ${ }^{7}$ Elevated levels of serum AGEs are observed in patients with NASH. ${ }^{8}$ Effects of AGEs are mediated by two categories of cytoplasmic membrane receptors. Receptor for AGEs (RAGE) is associated with increased oxidative stress, cell growth, and inflammation, ${ }^{9}$ The axis of AGE-RAGE-oxidative stress is involved in diabetic and cardiovascular complications. ${ }^{10}$ AGE receptor-1 (AGE-R1) is involved in detoxification and clearance of AGEs. ${ }^{11}$ In contrast to a dramatic increase in expression of RAGE in diabetic patients with high levels of plasma AGEs, ${ }^{12,13}$ the abundance of AGE-R1 is significantly reduced in diabetic patients. ${ }^{14}$

NASH is featured with fat accumulation and inflammation in the liver and accompanied with abnormally elevated levels of plasma leptin, ie, hyperleptinemia. ${ }^{15,16}$ Leptin, a $16-\mathrm{kD}$ adipose-derived protein, is the product of an obese gene $(o b)$ and is mainly responsible for control of food uptake and regulation of energy balance. ${ }^{17}$ Binding of leptin induces the 
activation of its receptors and downstream signaling cascades, including $\mathrm{JAK}_{2} /$ STAT3 and PI3K. ${ }^{17}$ Leptin-deficient mice (ob/ $o b$ ) fail to develop hepatic fibrosis during steatohepatitis or in response to chronic toxic liver injury. ${ }^{18}$ However, the administration of physiological levels of circulating leptin in $o b / o b$ mice by injecting exogenous leptin resumes liver fibrosis caused by dietary manipulations. ${ }^{18}$ On the other hand, thioacetamide-induced liver fibrosis is almost completely diminished in leptin receptor-deficient Zucker rats. ${ }^{19}$ These observations strongly imply that leptin might have a permissive role in the development of hepatic fibrosis.

Hepatic stellate cells (HSC) are the primary source of extracellular matrix (ECM) during hepatic fibrogenesis. ${ }^{20}$ Activation of quiescent HSC undergo profound phenotypic changes, including enhanced cell proliferation, de novo expression of $\alpha$-smooth muscle actin ( $\alpha$-SMA), overproduction of ECM and depletion of cellular lipids. ${ }^{20}$ Enormous evidence has demonstrated that leptin induces HSC activation in vitro and in vivo. ${ }^{21-24}$ Although NASH-related hepatic fibrosis is currently the target of significant scientific and clinical interest in the world, very few breakthroughs have occurred in therapeutic intervention of this disease. ${ }^{1}$ Research identifying novel, safe, and effective antifibrotic agents is, thus, of the highest priority. ${ }^{25}$ Most evolving antifibrotic therapies are aimed at inhibiting the activation of HSC. No effective medicine is currently available for treatment of obesity- and NASH-related hepatic fibrosis. ${ }^{26,27}$ The antioxidant curcumin, an ingredient derived from turmeric, is a promising dietary component for protection of the liver against fibrogenic insults. ${ }^{28,29}$ We and others have shown that curcumin inhibits the activation of HSC in vitro ${ }^{30-34}$ and protects the liver from fibrogenesis in vivo. ${ }^{28,35-37}$ Curcumin suppresses gene expression of leptin and its receptor and interrupts leptin signaling in HSC. ${ }^{24}$

We recently reported that AGEs inhibited gene expression of AGE-R1 and induced gene expression of RAGE in HSC, and stimulated HSC activation. ${ }^{38,39}$ Curcumin eliminated the effects of AGEs on the divergent regulation of gene expression of the receptors. ${ }^{38,39}$ Additional experiments are necessary to elucidate the underlying mechanisms. The aim of this study was to test our hypothesis that curcumin eliminated the effects of AGEs on the induction of gene expression of RAGE and the suppression of gene expression of AGE-R1 in HSC by interrupting AGE-caused activation of leptin signaling, leading to the inhibition of HSC activation. Culturing quiescent HSC on plastic plates causes spontaneous activation, mimicking the process seen in vivo, which provides a good model for elucidating underlying mechanisms of HSC activation and studying the potential therapeutic intervention of the process.

\section{MATERIALS AND METHODS}

\section{Materials and Chemicals}

AGEs were generated as we previously described. ${ }^{38,39}$ The AGE concentration was determined by measuring
AGE-specific fluorescence with excitation at $360 \mathrm{~nm}$ and emissions at $440 \mathrm{~nm}$. The fluorescence of the BSA control was used as a baseline, which was at least 70-fold less than that of the AGE-BSA sample. No contamination with insulin-like growth factor-1 and/or endotoxin was detected. Curcumin (purity $>94 \%$ ), recombinant leptin, the $\mathrm{JAK}_{2}$ inhibitor AG490, the PI3K inhibitor LY294002, N-acetyl-cysteine (NAC), and L-buthioninesulfoximine (BSO) were purchased from Sigma (St Louis, MO, USA).

\section{HSC Isolation and Cell Culture}

Male Sprague Dawley rats (200-250 g), C57BL/6J mice (20$40 \mathrm{~g})$, and leptin-deficient mice $(o b / o b)$ with C57BL/6J background $(20-40 \mathrm{~g})$ were purchased from the Harlan Laboratories (Indianapolis, IN, USA). They were housed in a temperature-controlled animal facility with a 12-h light, 12 -h dark cycle and allowed free access to regular chew and water ad libitum. HSC were isolated by the pronase-collagenase perfusion in situ before density gradient centrifugation, as we previously described. ${ }^{24}$ The animal protocol for the use of rats or mice was approved by Institutional Animal Care and Use Committee of Saint Louis University. It is noteworthy that all of experiments in this report used HSC from rats, except experiments using $o b / o b$, in which HSC were respectively isolated from leptin-deficient $\left(\mathrm{Lept}^{-1-}\right)$ mice and from wild-type $\left(\mathrm{Lept}^{+/+}\right.$) mice. Primary HSC were cultured in Dulbecco's modification of Eagle's medium (DMEM) supplemented with $20 \%$ of fetal bovine serum (FBS). HSC were passaged in DMEM with $10 \%$ of FBS. Semiconfluent HSC with 4-9 passages were used for experiments in this report. In some experiments, cells were cultured in serum-depleted media for $24 \mathrm{~h}$ before treatment, which rendered HSC more sensitive to exogenous leptin or AGEs. Cells were subsequently treated and cultured in serumdepleted media, which excluded the interference from other factors in FBS.

\section{Cell Growth Assays}

Cell growth was determined by using the CellTiter 96 aqueous non-radioactive cell proliferation assay kit (MTS assays) (Promega, Madison, WI, USA), following the protocol provided by the manufacturer. Each group was carried out in triplicates and repeated for at least three times. Results were expressed as fold changes in the density of viable cells.

\section{Immunoprecipitation and Western Blotting Analyses}

Whole-cell extracts were prepared from semiconfluent passaged HSC after treatment. Protein concentrations were determined by using the BCA Protein Assay kit according to the protocol provided by the manufacturer (Pierce, Rockford, IL, USA). Immunoprecipitation (IP), electrophoresis, transblotting, and immunodetection were conducted as previously described. ${ }^{24}$ Primary antibodies against leptin (sc-843), Ob-R (sc-8325), RAGE (sc-5563), AGE-R1 (sc-25558), phospho-JAK $_{2}$ (sc-16566-R), JAK 2 (sc-294), phospho-STAT3 
(sc-8059), STAT3 (sc-482), phospho-PI3K (sc-12929-R), PI3K (sc-423), NF-E2 p45-related factor 2 (Nrf2) (sc-13032), and horseradish peroxidase-conjugated secondary antibodies were purchased from Santa Cruz Biotechnology (Santa Cruz, CA, USA). Antibody against $\beta$-actin was purchased from Sigma-Aldrich (St Louis, MO, USA). $\beta$-Actin was used as an internal control for equal loading. Representatives were presented from three independent experiments. The commercial antibodies for detecting RAGE and AGE-R1 recognized the proteins from both rat and mouse. Results from western blotting analyses were representatives from at least three independent experiments.

\section{RNA Isolation and Real-Time PCR}

Preparation of total RNA and real-time PCR assays using SYBR green were carried out as we previously described. ${ }^{24}$ Total RNA was treated with deoxyribonuclease I before the synthesis of the first strand of cDNA. mRNA levels were expressed as fold changes after normalization with endogenous glyceraldehyde-3-phosphate dehydrogenase (GAPDH), as suggested by Schmittgen et al. ${ }^{40}$ Real-time PCR primers for leptin, Ob-Rb, and GAPDH were previously described. ${ }^{24}$ The primer sequences for measuring RAGE and AGE-R1 mRNA were shared by the genes from both rats and mice:

RAGE: 5'-GAATCCTCCCCAATGGTTCA-3' (F) $5^{\prime}$-GCCCGACACCGGAAAGT-3' (R).

AGE-R1: 5'-GCTCTGATATCGGTGACCCT-3' (F) $5^{\prime}$-TCGTAGTTGTGGTGGTCGAT-3' (R).

\section{Plasmids and Transient Transfection Assays}

The Nrf2 trans-activity luciferase reporter plasmid p8xAREluc, which contained eight copies of antioxidant response elements (AREs), was a gift from Dr Roland Wolf. ${ }^{41}$ The luciferase reporter plasmid pRAGE-luc, containing a fragment $(-2168 \mathrm{bp})$ of the mouse RAGE gene promoter, was previously described. ${ }^{39}$ The luciferase reporter plasmid pAGE-R1-luc with a fragment $(-3838 \mathrm{bp})$ of the mouse AGE-R1 gene promoter was previously described. ${ }^{38}$ The cDNA expression plasmid pNrf2, or pdn-Nrf2, respectively contained a full length of wild-type Nrf2 cDNA, or dominant-negative $(\mathrm{dn}) \mathrm{Nrf} 2 \mathrm{cDNA}$, subcloned in a cDNA expression plasmid. ${ }^{42}$ Both the plasmids were generously provided by Dr Raekil Park. ${ }^{42}$ The cDNA expression plasmids pwt-STAT3 and pdn-STAT3 were kindly provided by Dr Gerhard Müller-Newen. ${ }^{43}$ pwt-STAT3 contains a full length of wild-type STAT3 cDNA subcloned in the expression plasmid pcDNA 5FRT. However, in pdn-STAT3, a nucleotide ' $A$ ' was mutated to ' $\mathrm{T}$ ' in STAT3 cDNA, leading to the substitution of tyrosine 705 to phenylalanine and to the generation of dn STAT3. ${ }^{43}$ Semiconfluent HSC in 6-well cell-culture plates were transiently transfected using the Lipofectamine reagent (Invitrogen, Carlsbad, CA, USA), as we previously described. ${ }^{24}$ In experiments of transient transfection, $2 \mu \mathrm{g}$ of luciferase reporter plasmid DNA and $0.5 \mu \mathrm{g}$ of the $\beta$-galactosidase activity reporter plasmid
pSV- $\beta$-gal (Promega) were used in each well of a 6-well plate. Each sample was in triplicate in every experiment. Transfection efficiency was normalized by co-transfection of pSV- $\beta$-gal (Promega). $\beta$-Galactosidase activities were measured by using a chemiluminescence assay kit (Tropix, Bedford, MA, USA). Luciferase activities were measured by the luciferase assay system from Promega, using an automated luminometer (Turner Designs, Sunnyvale, CA, USA). Luciferase activities were presented in arbitrary units after normalization with $\beta$-galactosidase activities based on per microgram of proteins.

\section{Immunofluorescent Staining}

HSC were seeded in the slide flasks. After treatment, cells were fixed with $4 \%$ paraformaldehyde for $10 \mathrm{~min}$ and washed in $1 \times$ PBS for $5 \mathrm{~min}$, then blocked in a solution containing $5 \%$ normal goat serum, 1\% FBS, and 0.05\% TX100 in PBS, for $30 \mathrm{~min}$. Cells on slides were incubated in primary rabbit polyclonal antibodies against $\mathrm{Nrf} 2(1: 50)$ at $4{ }^{\circ} \mathrm{C}$ for overnight. After wash with PBS for 15 min for three times, cells were incubated with goat antirabbit secondary antibodies (1:500) conjugated with green-fluorescent Alexa Fluor ${ }^{\circledR} 488$ dye (A11008; Invitrogen) at room temperature for $1 \mathrm{~h}$. After wash in PBS, the slides were finally mounted with mounting solution containing 4'-6-diamidino-2-phenylindole (DAPI) in PBS for nuclei staining and evaluated under a fluorescent microscope (Leico DM4000B microscope; North Central Instruments, Plymouth, MN, USA). An oil lens $(\times 100)$ was used when photos were taken. Images were merged using Image J software. Views from immunostaining were representatives from at least three independent experiments.

\section{Analyses of the Activity of Glutamate-Cysteine Ligase} Glutamate-cysteine ligase (GCL) activities were determined at $25{ }^{\circ} \mathrm{C}$ spectrophotometrically using a coupled assay with pyruvate kinase and lactate dehydrogenase as we described previously. $^{34}$

\section{Determination of Cellular Glutathione}

The levels of cellular glutathione (GSH) and GSSG in HSC were, respectively, determined by using the enzyme immune assay kit GSH-400 (Cayman, Ann Arbor, MI, USA), following the protocol provided by the manufacturer, as we described previously. ${ }^{34}$

\section{Statistical Analysis}

Differences between means were evaluated using an unpaired two-sided Student's $t$ test $(P \leq 0.05$ was considered as significant). Where appropriate, comparisons of multiple treatment conditions with controls were analyzed by ANOVA with the Dunnett's test for post hoc analysis. It is noteworthy that results from real-time PCR were combined from three repeats and statistically analyzed $(n=3)$. Results from luciferase activity assays were from at least six repeats $(n \geq 6)$. 


\section{RESULTS}

AGEs Dose-Dependently Induced Gene Expression of Leptin and Leptin Receptor in Activated HSC In Vitro

We recently reported that AGEs stimulated HSC activation, likely by inhibiting gene expression of AGE-R1 and inducing gene expression of RAGE in HSC. ${ }^{38,39}$ In addition, the activation of HSC induced gene expression of leptin and activated its signaling, which, in turn, accelerated the activation of HSC. ${ }^{21,24,44,45}$ We, therefore, assumed that the effects of AGEs on the divergent regulation of the expression of the two receptor genes in HSC might be mediated by inducing gene expression of leptin and activating its signal transduction pathways, leading to the activation of HSC. To test the assumption, we started by evaluating the effect of AGEs on gene expression of leptin and its receptor Ob-Rb. Serum-starved HSC were treated with AGEs at indicated doses $(0-200 \mu \mathrm{g} / \mathrm{ml})$ in serum-depleted media for $24 \mathrm{~h}$. The subsequent culture in serum-depleted media excluded the interference from factors in FBS. Total RNA or whole-cell extracts were prepared for real-time PCR or western blotting analyses. As shown in Figure 1a, AGEs dosedependently enhanced the mRNA level of leptin and Ob-Rb in passaged HSC. Further experiments by IP and western blotting analyses revealed that AGEs elevated the protein abundance of leptin and Ob-R in the cells. The results

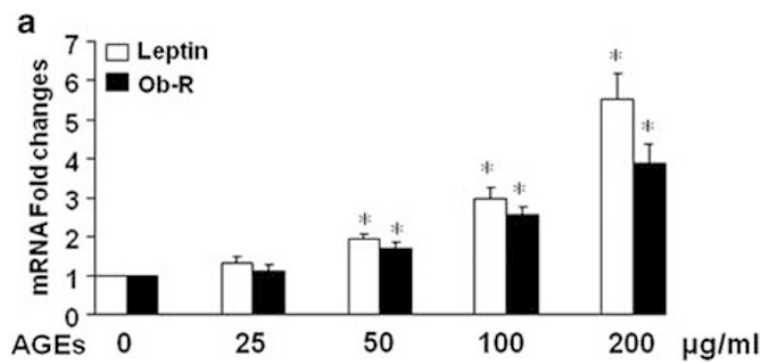

b
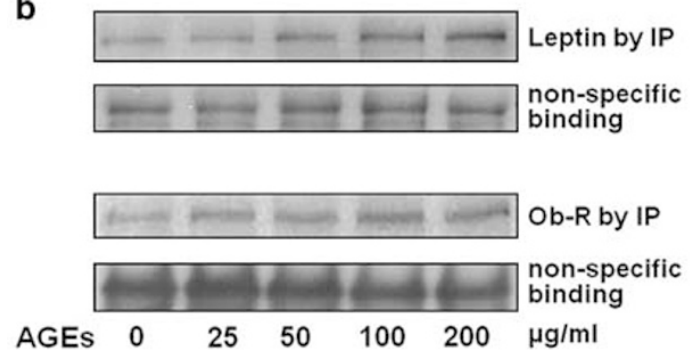

Figure 1 AGEs dose-dependently induced gene expression of leptin and its receptor Ob-R in activated HSC in vitro. Serum-starved HSC were treated with AGEs as indicated. Total RNA or whole-cell extracts were prepared. (a) Real-time PCR analyses of leptin and Ob-Rb mRNA. Values were expressed as mRNA fold changes (means \pm s.d.) $(n=3)$. ${ }^{*} P<0.05$ vs the untreated control (the corresponding first column). (b) Western blotting analyses of immune-precipitated leptin and Ob-R. Nonspecifically recognized heavy chain was used as an invariant control for equal loading. Representatives were presented from three independent experiments. collectively demonstrated that AGEs dose-dependently stimulated gene expression of leptin and its receptor Ob-R in HSC in vitro.

\section{Leptin Dose-Dependently and Differentially Regulated Gene Expression of RAGE and AGE-R1 in Activated HSC In Vitro}

To determine the role of leptin in regulating gene expression of RAGE and AGE-R1 in HSC, serum-starved cells were treated with leptin at different doses $(0-150 \mathrm{ng} / \mathrm{ml})$ in serumdepleted media for $24 \mathrm{~h}$. Total RNA or whole-cell extracts were prepared. As shown in Figure 2a, compared with untreated control (the corresponding first column), leptin dose-dependently and differentially altered the mRNA levels of RAGE and AGE-R1 in HSC by elevating the mRNA level of RAGE and reducing the mRNA content of AGE-R1 (the corresponding second to sixth columns). Additional western blotting analyses assured the observation and indicated that leptin increased the protein abundance of RAGE and reduced the content of AGE-R1 in HSC in a dosedependent manner (Figure 2b). Taken together, these data demonstrated that leptin dose-dependently and differentially regulated gene expression of RAGE and AGE-R1 in activated HSC in vitro.

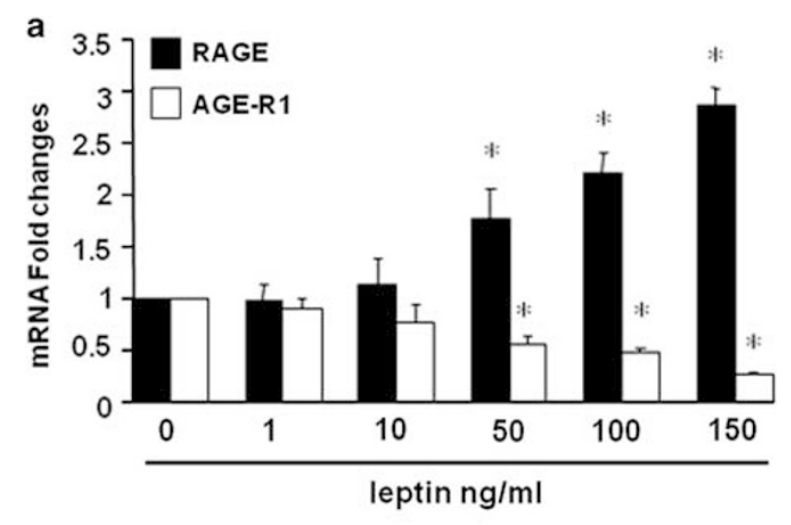

b

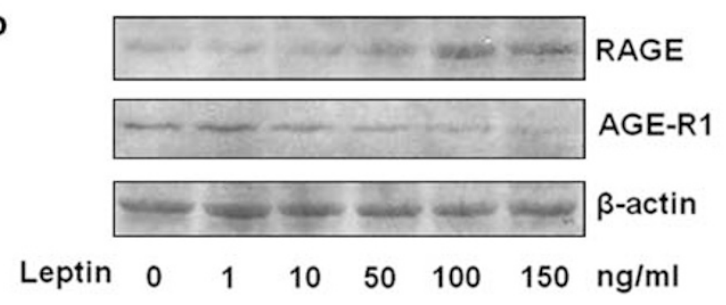

Figure 2 Leptin dose-dependently and differentially regulated gene expression of RAGE and AGE-R1 in activated HSC in vitro. Serum-starved HSC were treated with leptin $(100 \mathrm{ng} / \mathrm{ml})$ as indicated. Total RNA or whole-cell extracts were prepared. (a) Real-time PCR analyses of RAGE and AGE-R1 mRNA. Values were expressed as mRNA fold changes (means \pm s.d.) $(n=3) .{ }^{*} P<0.05$ vs the untreated control (the corresponding first column). (b) Western blotting analyses of RAGE and AGE-R1. $\beta$-Actin was used as an invariant control for equal loading. Representatives were presented from three independent experiments. 
Leptin-Deficient HSC were Irresponsive to AGEs in Cell Growth and in the Regulation of Gene Expression of RAGE and AGE-R1, Which were Dose-Dependently Restored by Exogenous Leptin

We recently showed that AGEs dose-dependently induced the activation of HSC by stimulating cell growth and the expression of pro-fibrogenic genes. ${ }^{38}$ We assumed that leptin might mediate the stimulatory effects of AGEs. To test the assumption, HSC were isolated from wild-type mice or from leptin-deficient $(o b / o b)$ mice. After serum starvation in serum-depleted media for $24 \mathrm{~h}$, both genotypes of passaged mouse HSC were respectively pretreated with AGEs at indicated concentrations $(0-100 \mu \mathrm{g} / \mathrm{ml})$ for $1 \mathrm{~h}$ with or without the addition of exogenous recombinant leptin at indicated concentrations for additional $24 \mathrm{~h}$. Cell growth was determined by using MTS assays. As shown in Figure 3a, AGEs showed no effect on cell growth in $o b / o b$ HSC (the first to fourth columns). In great contrast, in the presence of exogenous leptin $(20 \mathrm{ng} / \mathrm{ml})$, AGEs caused a dose-dependent increase in cell growth of the $o b / o b$ HSC (the fifth to eighth columns). Further experiments in Figure $3 b$ showed that AGEs caused, as expected, an increase in cell growth of HSC from wild-type mice (the first to fourth of the white columns), but not HSC from $o b / o b$ mice (the first to fourth of the black columns). However, exogenous leptin facilitated the stimulatory role of AGEs at $100 \mu \mathrm{g} / \mathrm{ml}$ and caused a dose-dependent increase in both genotypes of HSC (the fifth to eighth columns). Nevertheless, the stimulatory effect of leptin on cell growth in $o b / o b$ HSC was significantly weaker (black columns), compared with that in wild-type HSC (white columns). Taken together, the results indicated that leptin was a necessary factor and had a critical role in the process of the AGE-caused cell growth of HSC in vitro.

To explore the underlying mechanisms, we presumed that leptin critically mediated the effect of AGEs on the divergent regulation of gene expression of RAGE and AGE-R1 in HSC. To test the presumption, serum-starved leptin-deficient HSC were treated with AGEs at indicated concentrations $(0-100 \mu \mathrm{g} / \mathrm{ml})$ with or without exogenous leptin $(20 \mathrm{ng} / \mathrm{ml})$ for $24 \mathrm{~h}$. Whole-cell extracts were prepared. As shown in Figure $3 \mathrm{c}$ by western blotting analyses, AGEs had no apparent impact on the abundance of RAGE or AGE-R 1 in $o b / o b$ HSC (the first to fourth wells). However, in the presence of exogenous leptin at $20 \mathrm{ng} / \mathrm{ml}$, AGEs significantly reduced the level of AGE-R1 and increased the abundance of RAGE in a dose-dependent manner in $o b / o b$ HSC (the fifth to eighth wells), suggesting the necessity of leptin in the process. It is noteworthy that unlike rat RAGE, mouse RAGE always shows two bands detected by antibodies used in this report. It has been reported that RAGE has variant splicing products in mammals. ${ }^{46}$ Taken together, these results indicated that leptin was necessary for AGEs to stimulate cell growth and mediated the impact of AGEs on the divergent regulation of gene expression of RAGE and AGE-R1 in HSC.
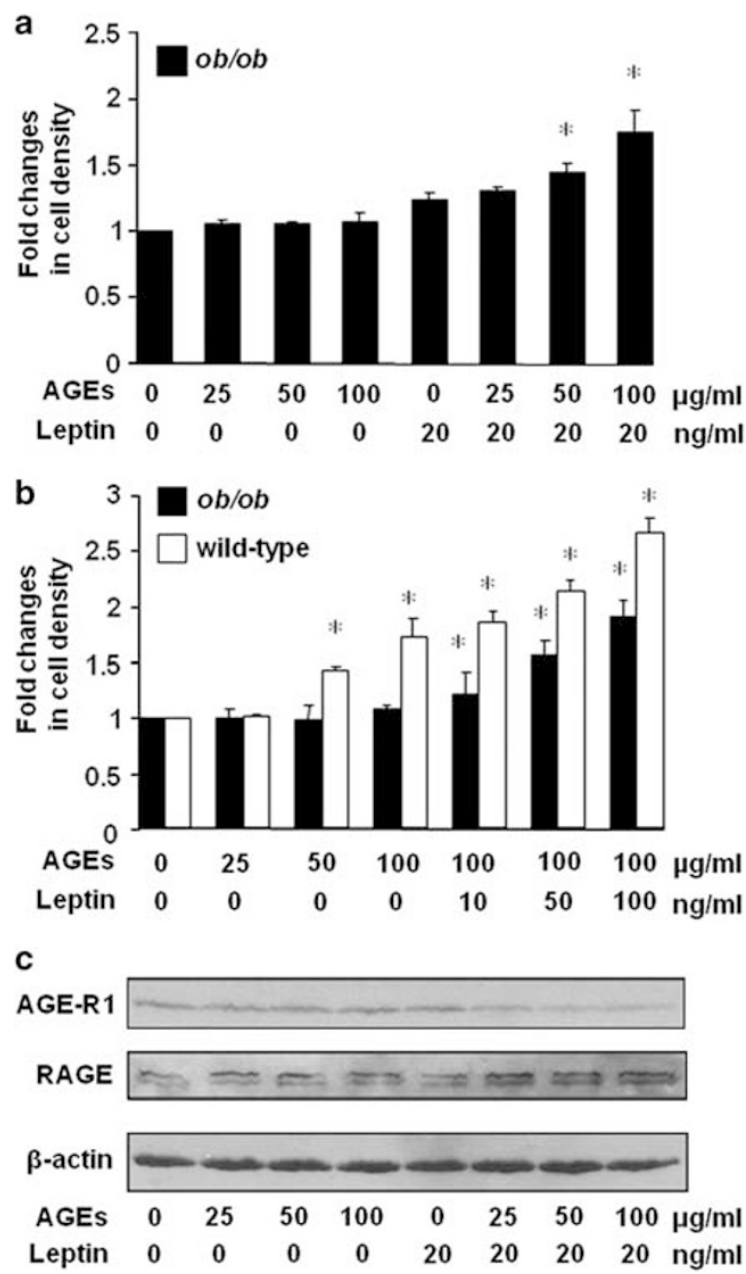

Figure 3 Leptin-deficient HSC were irresponsive to AGEs in cell growth and in the regulation of gene expression of RAGE and AGE-R1, which were dose-dependently restored by exogenous leptin. HSC were isolated from wild-type mice or from leptin-deficient $(o b / o b)$ mice. After serum starvation in serum-depleted media for $24 \mathrm{~h}$, passaged mouse HSC were pretreated with AGEs at indicated concentrations for $1 \mathrm{~h}$ with or without the addition of exogenous recombinant leptin at indicated concentrations for additional $24 \mathrm{~h}$. (a, b) Cell growth was determined by colorimetric MTS assays. Results were expressed as fold changes in cell density. Values were expressed as means \pm s.d. $(n=3)$. ${ }^{*} P<0.05$ vs the untreated control (the fifth column). (c) Western blotting analyses of RAGE and AGE-R1. $\beta$-Actin was used as an invariant control for equal loading. Representatives were presented from three independent experiments.

Inhibition of the Activation of $\mathrm{JAK}_{2} / \mathrm{STAT3}$ or PI3K/AKT Abrogated the Impacts of AGEs or Leptin on the Divergent Regulation of Gene Expression of RAGE and AGE-R1 in HSC

Prior studies have shown that $\mathrm{JAK}_{2} / \mathrm{STAT}_{3}$ and PI3K/AKT are the major intermediators in signal transduction cascades activated by leptin. ${ }^{47,48}$ To explore the role of leptin signaling pathways in the impact of AGEs on the divergent regulation of gene expression of RAGE and AGE-R1, serum-starved HSC were pretreated with AG490 $(20 \mu \mathrm{M})$, a specific $\mathrm{JAK}_{2}$ 
inhibitor, or LY294002 (20 $\mu \mathrm{M})$, a selective inhibitor of PI3K/ AKT, for $1 \mathrm{~h}$ before the addition of leptin $(100 \mathrm{ng} / \mathrm{ml})$ or AGEs $(100 \mu \mathrm{g} / \mathrm{ml})$ for additional $24 \mathrm{~h}$. Total RNA or wholecell extracts were prepared for real-time PCR or western blotting analyses. As shown in Figures $4 \mathrm{a}$ and b, compared with the untreated control (the corresponding first column or well), leptin as well as AGEs, as expected, elevated the levels of RAGE transcript and protein and reduced the contents of AGE-R1 mRNA and protein (the corresponding second or fourth columns or wells). It was noteworthy that the differential effects of leptin or AGEs were abrogated by the $\mathrm{JAK}_{2}$ inhibitor AG490 (the corresponding third or fifth columns or wells). Similarly, the inhibition of PI3K/AKT by LY294002 (LY) also eliminated the effects of leptin or AGEs on the divergent regulation of gene expression of RAGE and AGE-R1 (Figures $4 \mathrm{c}$ and $\mathrm{d}$ ).

To eliminate potential false effects from the chemical inhibitors used in the experiments, additional experiments were conducted. HSC were co-transfected with the rage or age-r1 promoter luciferase reporter plasmid pRAGE-luc or pAGE-R1-luc $c^{38,39}$ and a cDNA expression plasmid pdn-STAT3 or pwt-STAT3. ${ }^{43}$ The plasmids pdn-STAT3 and pwt-STAT3, respectively, encode dn STAT3 and wild-type STAT3 ${ }^{43} \mathrm{~A}$ total of $4.0 \mu \mathrm{g}$ of a DNA mixture was added to each well of cells in 6 -well culture plates, including $2 \mu \mathrm{g}$ of pRAGE-luc or pAGER1-luc, $0.5 \mu \mathrm{g}$ of pSV- $\beta$-gal and $1.5 \mu \mathrm{g}$ of pdn-STAT3, or pwt-STAT3, at various doses plus the empty vector pcDNA. The latter was used to ensure an equal amount of total DNA in transfection assays. After recovery, cells were serum starved for $4 \mathrm{~h}$ before the treatment with or without AGEs $(100 \mu \mathrm{g} / \mathrm{ml})$ in serum-depleted media for additional $24 \mathrm{~h}$. As shown in Figure $4 \mathrm{e}$ by luciferase activity assays, forced expression of $\mathrm{dn}$ STAT3 dose-dependently attenuated the effects of AGEs on divergently regulating the promoter activity of RAGE and AGE-R1 genes in HSC (the second to sixth columns, compared with the corresponding first column). In contrast, forced expression of wild-type STAT3 slightly, but not significantly, enhanced the effects of AGEs on the divergent regulation of the promoter activity of RAGE and AGE-R1 genes (the seventh column, compared with the corresponding second column). Forced expression of dn STAT3 or wildtype STAT3, without AGEs, had no apparent impact on the promoter activity of the two genes in the cells (the eighth or nineth column, compared with the corresponding first column). These results collectively indicated that the activation of JAK $/$ STAT3 and PI3K/AKT had a vital role in the effects of AGEs or leptin on the divergent regulation of gene expression of RAGE and AGE-R1 in HSC.

\section{AGEs Activated JAK 2 /STAT3 and PI3K/AKT in HSC, Leading to the Divergent Regulation of RAGE and AGE-R1, Which was Interrupted by Curcumin}

We recently reported that the antioxidant curcumin eliminated the effect of AGEs on stimulating HSC activation by inducing gene expression of AGE-R1 and inhibiting gene

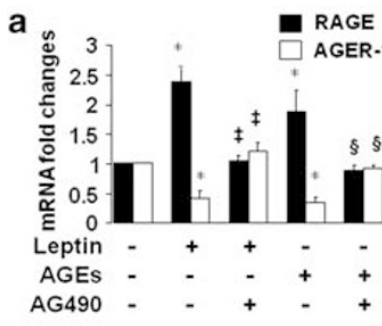

b

C
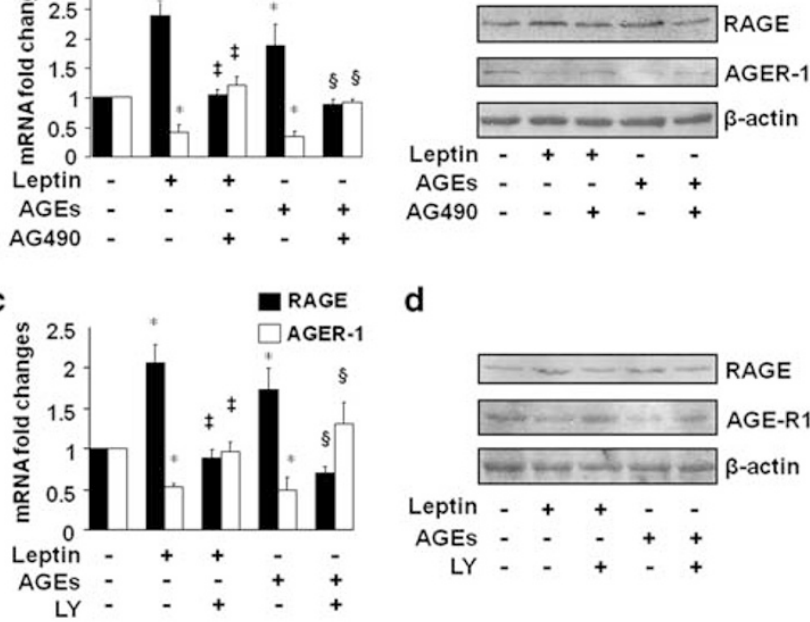

d

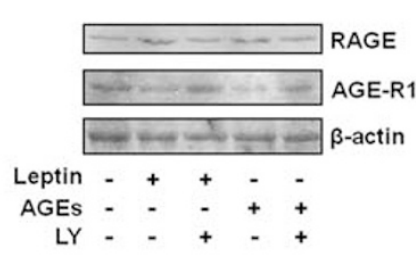

e

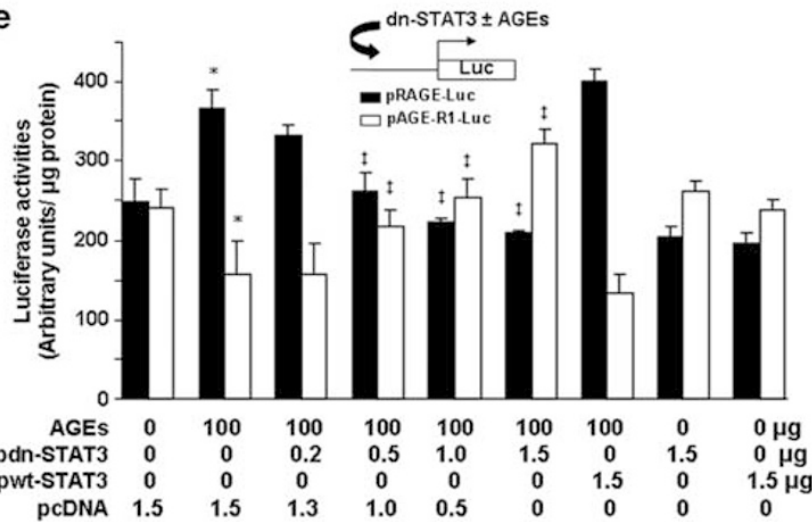

Figure 4 Inhibition of the activation of $\mathrm{JAK}_{2} / \mathrm{STAT3}$ or PI3K/AKT abrogated the impacts of AGEs or leptin on the divergent regulation of gene expression of RAGE and AGE-R1 in HSC. Serum-starved HSC were pretreated with AG490 $(20 \mu \mathrm{M})$, a specific $\mathrm{JAK}_{2}$ inhibitor, or LY294002 $(20 \mu \mathrm{M})$, a selective inhibitor of PI3K/AKT, for $1 \mathrm{~h}$ before the addition of leptin $(100 \mathrm{ng} / \mathrm{ml})$ or AGEs $(100 \mu \mathrm{g} / \mathrm{ml})$ for additional $24 \mathrm{~h}$. Total RNA or whole-cell extracts were prepared for real-time PCR or western blotting analyses of RAGE or AGE-R1. (a, b) Cells were treated with AG490 and analyzed by real-time PCR (a) or western blotting analyses (b); (c, d) Cells were treated with LY294002 (LY) and analyzed by real-time PCR (c) or western blotting analyses (d). Values in $(\mathbf{a}, \mathbf{c})$ were expressed as mRNA fold changes (means \pm s.d.) $(n=3) .{ }^{*} P<0.05$ vs the untreated control (the corresponding first column); ${ }^{\ddagger} P<0.05$ vs the cells treated with leptin only (the corresponding second column); ${ }^{\S} P<0.05$ vs the cells treated with AGEs only (the corresponding fifth column). $\beta$-Actin was used as an invariant control in western blotting analyses for equal loading. Representatives were presented from three independent experiments. (e). Luciferase activity assays of HSC co-transfected with the rage or age-r 1 promoter luciferase reporter plasmid pRAGE-luc or pAGE-R1-luc and a CDNA expression plasmid pdn-STAT3 or pwt-STAT3, followed by the treatment with or without AGEs $(100 \mu \mathrm{g} / \mathrm{ml})$ for $24 \mathrm{~h}$. The plasmids pdnSTAT3 and pwt-STAT3, respectively, encode dominant-negative STAT3 and wild-type STAT3. Luciferase activities were expressed as relative units after normalization with $\beta$-galactosidase activities (means \pm s.d., $n=6$ ). ${ }^{*} P<0.05$ vs the untreated control (the corresponding first column); ${ }^{\ddagger} P<0.05$ vs the cells only transfected with pRAGE-luc or pAGE-R1-luc, without pdn-STAT3 or pwt-STAT3 (the corresponding second column). 
expression of RAGE in HSC. ${ }^{38,39}$ The underlying mechanisms remain largely to be defined. We presumed that AGEs activated leptin signaling and the activation of $\mathrm{JAK}_{2} / \mathrm{STAT} 3$ and PI3K/AKT in HSC, leading to the divergent regulation of RAGE and AGE-R1, and that curcumin eliminated these effects of AGEs by interrupting the activation of $\mathrm{JAK}_{2} / \mathrm{STAT} 3$ and PI3K/AKT. To begin to test the presumption, passaged HSC were treated with the $\mathrm{JAK}_{2}$ inhibitor AG490 at different doses $(0-20 \mu \mathrm{M})$ for $24 \mathrm{~h}$. Whole-cell extracts were prepared for western blotting analyses. As shown in Figure 5a, the inhibition of $\mathrm{JAK}_{2}$ by AG490 reduced the abundance of RAGE, meanwhile increased the content of AGE-R1 in a dose-dependent manner. The results confirmed and highlighted the vital role of the activation of $\mathrm{JAK}_{2} / \mathrm{STAT} 3, \mathrm{PI} 3 \mathrm{~K} /$ AKT in the divergent regulation of gene expression of RAGE and AGE-R1 in HSC. To test our presumption, serum-starved HSC were pretreated with curcumin at different concentrations $(0-30 \mu \mathrm{M})$ for $1 \mathrm{~h}$ before the treatment with or without AGEs $(100 \mu \mathrm{g} / \mathrm{ml})$ for additional $30 \mathrm{~min}$. Pilot experiments indicated that AGEs rapidly activated its signaling in HSC and reached its peak within 20-30 min (unpublished observations). Whole-cell extracts were prepared for western blotting analyses. As shown in Figures 5b-d, compared with the untreated control (the corresponding first wells), AGEs elevated the levels of phosphorylation of $\mathrm{JAK}_{2}$ (Figure $5 \mathrm{~b}$ ), STAT3 (Figure 5c), and PI3K (Figure 5d) (the corresponding second wells), which were eliminated by curcumin in a dosedependent manner (the corresponding third to sixth wells). These results supported our presumption and demonstrated that curcumin abolished the role of AGEs in the activation of $\mathrm{JAK}_{2} / \mathrm{STAT}_{3}$ and PI3K/AKT, which might lead to the elimination of the effect of AGEs on the divergent regulation of RAGE and AGE-R1 in HSC.
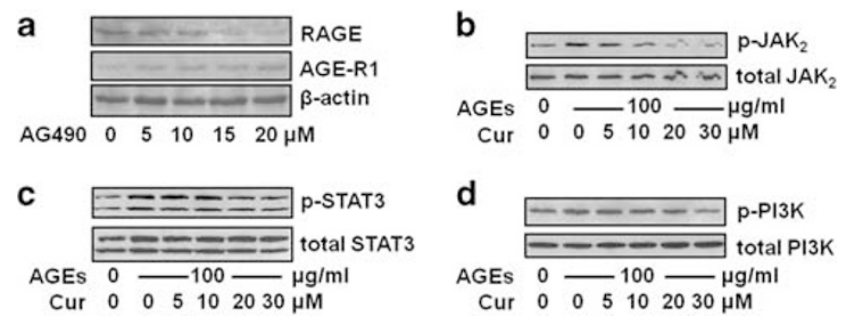

Figure 5 AGEs activated $\mathrm{JAK}_{2} / \mathrm{STAT3}$ and PI3K/AKT in HSC, likely leading to the divergent regulation of RAGE and AGE-R1, which was interrupted by curcumin. (a) Western blotting analyses of RAGE and AGE-R1 in passaged HSC treated with AG490 at indicated concentrations for $24 \mathrm{~h}$. $\beta$-Actin was used as an invariant control for equal loading.

Representatives were presented from three independent experiments. (b-d). Serum-starved HSC were pretreated with curcumin (Cur) at indicated concentrations $(0-30 \mu \mathrm{M})$ for $1 \mathrm{~h}$ before the treatment with or without AGEs $(100 \mu \mathrm{g} / \mathrm{ml})$ for additional $30 \mathrm{~min}$. Whole-cell extracts were prepared for western blotting analyses of phosphorylated JAK $2\left(p-\mathrm{JK}_{2}\right)$ (b), phosphorylated STAT3 (p-STAT3) (c), and phosphorylated PI3K (p-PI3K) (d). Representatives were presented from three independent experiments. Corresponding total proteins were used as internal invariant controls for equal loading.

\section{Curcumin Eliminated the Impacts of Leptin on Differentially Regulating Gene Expression of RAGE and AGE-R1}

To explore the role of curcumin in the interruption of the AGE-activated leptin signaling and the elimination of the AGE-caused divergent regulation of RAGE and AGE-R1, HSC were transfected with the rage or age-r1 promoter luciferase reporter plasmid pRAGE-luc or pAGE-R1-luc. Each of the plasmid contained a fragment of the gene promoter of RAGE or AGE-R1 subcloned in a luciferase reporter plasmid. ${ }^{38,39}$ After overnight recovery, cells were serum starved for $4 \mathrm{~h}$ and subsequently pretreated with curcumin $(0-30 \mu \mathrm{M})$ for $1 \mathrm{~h}$ before the treatment with or without leptin $(100 \mathrm{ng} / \mathrm{ml})$ in serum-depleted media for additional $24 \mathrm{~h}$. Luciferase activity assays were conducted. As shown in Figure 6a, compared with the untreated control (the corresponding first column), leptin significantly increased the luciferase activity in cells transfected with pRAGE-luc (the second black column) and reduced the luciferase activity in cells transfected with pAGE-R1-luc (the second white column). Curcumin dose-dependently eliminated the divergent effects of leptin (the corresponding third to sixth columns). To further explore the observations, serum-starved HSC were similarly pretreated with curcumin $(0-30 \mu \mathrm{M})$ for $1 \mathrm{~h}$ before the treatment with or without leptin $(100 \mathrm{ng} / \mathrm{ml})$ in serumdepleted media for additional $24 \mathrm{~h}$. Total RNA or whole-cell extracts were prepared. Results from real-time PCR (Figure 6b) and western blotting analyses (Figure 6c) substantiated the above observation at the levels of transcript and protein. These results indicated that curcumin eliminated the impacts of leptin on differentially regulating gene expression of RAGE and AGE-R1 in HSC. In summary, results in Figures 4-6 collectively supported our presumptions and revealed that the activation of leptin signaling and the $\mathrm{JAK}_{2} / \mathrm{STAT} 3, \mathrm{PI} 3 \mathrm{~K} / \mathrm{AKT}$ signal pathway had a critical role in the AGE-caused divergent regulation of RAGE and AGE-R1 in HSC. Curcumin inhibited the activation of $\mathrm{JAK}_{2} /$ STAT3 and PI3K/AKT and eliminated the effects of AGEs, or leptin, on the divergent regulation of the expression of the genes in HSC.

\section{Like Leptin, AGEs Inhibited the Activation of Nrf2 in HSC, Which was Abolished by Curcumin}

We previously reported that leptin-induced oxidative stress in HSC, which was dose-dependently attenuated by curcumin..$^{24}$ However, the underlying mechanisms remain largely elusive. Activation of the transcription factor Nrf2 is initiated by phosphorylation of Nrf2, leading to its translocation to the nucleus where it binds to antioxidant/electrophile responsive elements (AREs) in the promoter of target genes. ${ }^{49,50} \mathrm{We}$ postulated that the AGE-caused activation of leptin signaling stimulated oxidative stress, and that curcumin attenuated the stimulatory effect by inducing the activation of Nrf2, leading to the elimination of the effect of AGEs on the divergent regulation of gene expression of RAGE and AGE-R1. To test 
a

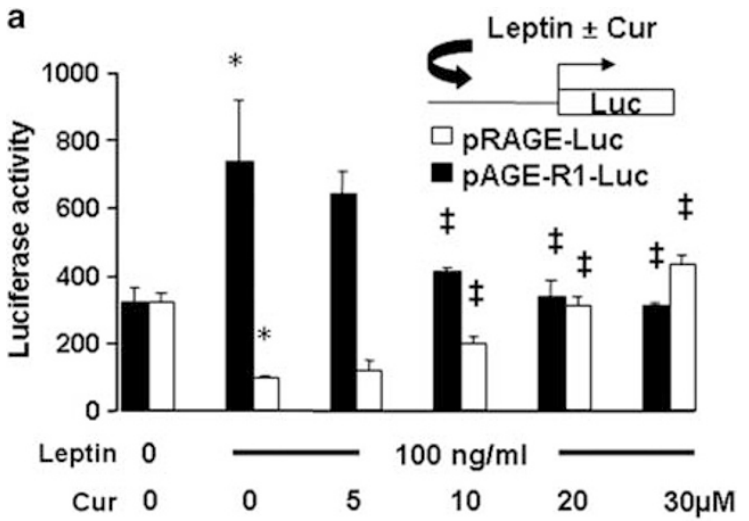

b

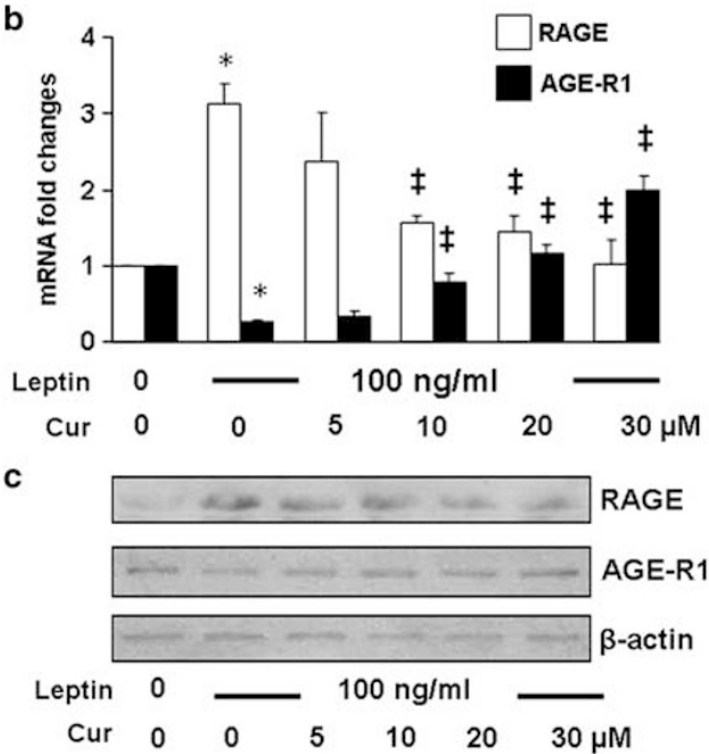

Figure 6 Curcumin eliminated the impacts of leptin on differentially regulating gene expression of RAGE and AGE-R1. Serum-starved HSC were treated with or without leptin $(100 \mathrm{ng} / \mathrm{ml})$ in the presence of curcumin (Cur) at indicated concentrations in serum-depleted DMEM for $24 \mathrm{~h} .{ }^{*} P<0.05$ vs the untreated control (the corresponding first column); ${ }^{\ddagger} P<0.05$ vs the cells treated with leptin only (the corresponding second column). (a) Luciferase activity assays of cells transiently transfected with the plasmid pRAGE-luc or pAGE-R1-luc. Luciferase activities were expressed as relative units after normalization with $\beta$-galactosidase activities (means \pm s.d., $n \geq 6$ ). The inset denoted the luciferase reporter plasmids in use and the application of leptin with or without Cur to the system; (b) Real-time PCR analyses of RAGE and AGE-R1 mRNA. Values were expressed as mRNA fold changes (means \pm s.d.) $(n=3)$; (c) Western blotting analyses of RAGE and AGE-R1. $\beta$-Actin was used as an invariant control for equal loading. Representatives were presented from three independent experiments.

the postulation, first of all, we needed to determine whether AGEs or leptin could inhibit the activation of Nrf2 in HSC, and whether curcumin could eliminate the inhibitory effect. Serum-starved HSC were pretreated with curcumin $(20 \mu \mathrm{M})$ for $1 \mathrm{~h}$ before the addition of leptin $(100 \mathrm{ng} / \mathrm{ml})$ or AGEs $(100 \mu \mathrm{g} / \mathrm{ml})$ for additional $24 \mathrm{~h}$. Immunofluorescent stain was used to determine the location of Nrf2 in the cells. As demonstrated in Figure 7a, Nrf2 was evenly distributed in both the cytoplasm and the nuclei in the untreated control HSC. Like leptin, the treatment with AGEs resulted in the accumulation of Nrf2 in the cytoplasm of HSC, indicating the inhibition of Nrf2 activation. It was of interest to observe that the pretreatment with curcumin eliminated the impact of leptin or AGEs and induced the translocation of Nrf2 into nuclei. These observations suggested that like leptin, AGEs inhibited Nrf2 activation in HSC, which was eliminated by curcumin.

To further evaluate the impact of AGEs or leptin with or without curcumin on the activation of Nrf2 in HSC, HSC were transfected with the Nrf2 trans-activity luciferase reporter plasmid p8XARE-luc, which contained eight copies of ARE subcloned in a luciferase reporter plasmid. ${ }^{41}$ After overnight recovery, cells were serum starved for $4 \mathrm{~h}$ and subsequently pretreated with curcumin at different doses $(0-30 \mu \mathrm{M})$ for $1 \mathrm{~h}$ before the addition of AGEs $(100 \mu \mathrm{g} / \mathrm{ml})$, or leptin $(100 \mathrm{ng} / \mathrm{ml})$, for additional $24 \mathrm{~h}$. As shown in Figure $7 \mathrm{~b}$ and in Supplementary 1 by luciferase activity assays, AGEs, like leptin, significantly reduced luciferase activities in the cells (the corresponding second columns). However, the pretreatment with curcumin dose-dependently abrogated the inhibitory effect of AGEs (or leptin), and increased luciferase activities (the corresponding third to fifth columns). Results for leptin treatment were presented in Supplementary 1. Taken together, these results indicated that like leptin, AGEs inhibited the activation of Nrf2 in HSC, which was abrogated by curcumin.

\section{Forced Expression of Nrf2, or dn-Nrf2, cDNA Showed Opposite Impacts on the Regulation of the Promoter activities of RAGE and AGE-R1 Genes in HSC}

To further test our aforesaid postulation and to elucidate the role of Nrf2 in the AGE-caused divergent regulation of gene expression of RAGE and AGE-R1, passaged HSC were co-transfected with the plasmid pRAGE-luc, or pAGE-R1luc, plus the cDNA expression plasmid pNrf2 or pdn-Nrf2. The plasmids pNrf2 and pdn-Nrf2, respectively, contained a full length of wild-type Nrf2 cDNA, or dn Nrf2 cDNA, subcloned in a cDNA expression plasmid. ${ }^{42}$ After overnight recovery, cells were serum starved for $4 \mathrm{~h}$ and subsequently treated with or without AGEs $(100 \mu \mathrm{g} / \mathrm{ml})$, or curcumin $(20 \mu \mathrm{M})$ for additional $24 \mathrm{~h}$. Luciferase activity assays were conducted in the cells. As shown in Figure 8a, AGEs, as expected, significantly activated the rage promoter demonstrated by elevating the luciferase activity in cells with pRAGE-luc, and inhibited the age-r1 promoter shown by reducing the luciferase activity in cells with pAGE-R1-luc (the corresponding second columns). It was of interest to observe that forced expression of Nrf2 cDNA dosedependently diminished the effect of AGEs on the divergent regulation of the promoter activity of RAGE and AGE-R1 genes (the corresponding third to seventh columns). 

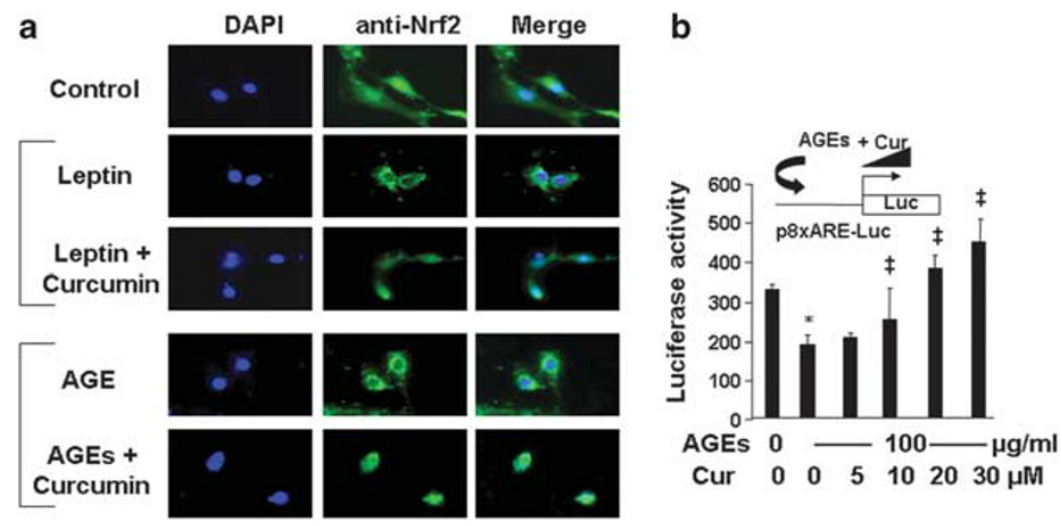

Figure 7 AGEs, like leptin, inhibited the activation of Nrf2 in HSC, which was abolished by curcumin. (a) Serum-starved HSC were pretreated with curcumin (Cur) $(20 \mu \mathrm{M})$ for $1 \mathrm{~h}$ before the addition of leptin $(100 \mathrm{ng} / \mathrm{ml})$ or AGEs $(100 \mu \mathrm{g} / \mathrm{ml})$ for additional $24 \mathrm{~h}$. Control cells received no treatment. Cells were fixed with $4 \%$ paraformaldehyde for the subsequent immunostain of Nrf2. An oil lens $(\times 100)$ was used. Views from immunostaining were representatives from at least three independent experiments. (b) HSC were transiently transfected with the plasmid p8xARE-luc. After recovery, cells were treated with or without AGEs $(100 \mu \mathrm{g} / \mathrm{ml})$ in the presence of curcumin at indicated concentrations in serum-depleted DMEM for $24 \mathrm{~h}$. Luciferase activity assays were conducted. Luciferase activities were expressed as relative units after normalization with $\beta$-galactosidase activities (means \pm s.d., $n \geq 6$ ). ${ }^{*} P<0.05$ vs the untreated control cells (the corresponding first column). ${ }^{\ddagger} P<0.05$ vs the cells treated with AGEs only (the second column). The inset denoted the plasmid p8xARE-luc in use and the application of AGEs plus curcumin (Cur) to the system.
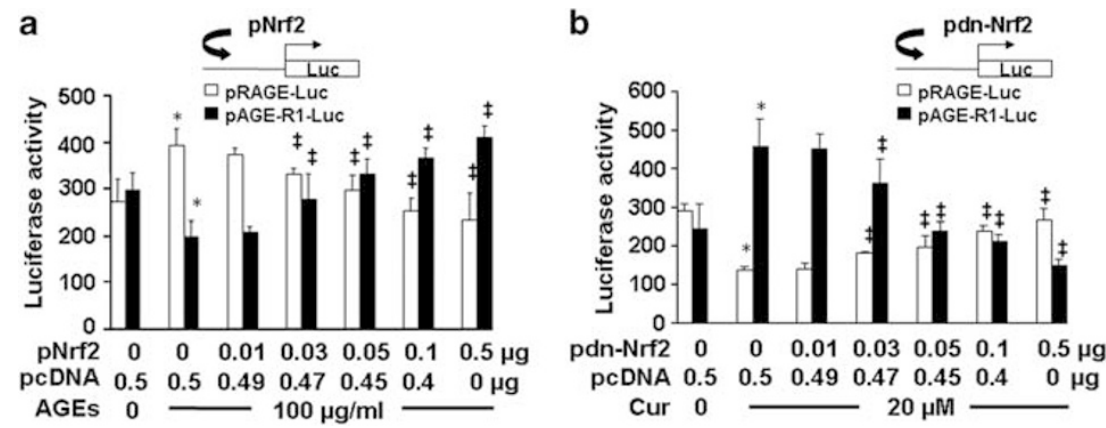

Figure 8 Forced expression of Nrf2, or dn-Nrf2, cDNA showed opposite impacts on the regulation of the promoter activities of RAGE and AGE-R1 genes in HSC. Passaged cells were co-transfected with the luciferase report plasmid pRAGE-luc (a), or pAGE-R1-luc (b), and the cDNA expression plasmid pNrf2 (a), or pdn-Nrf2 cDNA (b), at various doses plus the empty vector pcDNA. The latter was used to ensure equal amount of total DNA in the co-transfection. After recovery, cells were serum starved for $4 \mathrm{~h}$ and treated with or without AGEs (100 $\mu \mathrm{g} / \mathrm{ml})(\mathbf{a})$, or curcumin (Cur) (20 $\mu \mathrm{M})(\mathbf{b})$, in serum-depleted DMEM for $24 \mathrm{~h}$. Luciferase activities were analyzed and expressed as relative units after normalization with $\beta$-galactosidase activities (means \pm s.d., $n=6$ ). ${ }^{*} P<0.05$ vs the untreated control cells (the corresponding first column). ${ }^{\ddagger} P<0.05$ vs the cells treated with AGEs (a), or curcumin only (the corresponding second column) (b). The insets denoted the co-transfection of HSC with a luciferase reporter plasmid plus a cDNA expression plasmid in the system.

On the other hand in Figure 8b, in contrast to AGEs, curcumin, as expected, significantly reduced the luciferase activity in cells with pRAGE-luc and increased the luciferase activity in cells with pAGE-R1-luc (the corresponding second columns). Forced expression of dn-Nrf2 cDNA, which prevented Nrf2 from activation, dose-dependently diminished the differential effects of curcumin on the promoter activity of RAGE and AGE-R1 genes (the corresponding third to seventh columns). Taken together, these results demonstrated that forced expression of Nrf2 or dn-Nrf2 cDNA showed opposite impacts and differentially regulated the promoter activities of RAGE and AGE-R1 genes in HSC. In summary, the results in Figures 7 and 8 collectively indicated that the activation of Nrf2 had differential impacts on the promoter activity of RAGE and AGE-R1 genes. AGEs, as well as leptin, inhibited the activation of Nrf2 and ARE, leading to the divergent regulation of the promoter activity of RAGE and AGE-R1 genes in HSC, which were eliminated by curcumin.

\section{AGEs Decreased the Abundance of GCL and Its Activity in HSC, Leading to the Reduction in the Content of Cellular GSH, Which was Eliminated by Curcumin}

GCL is a key rate-limiting enzyme in de novo synthesis of GSH, a main non-protein thiol. ${ }^{51} \mathrm{GSH}$ reacts with reactive oxygen species (ROS) or functions as a cofactor of antioxidant enzymes, leading to the attenuation of oxidative 
stress. During that process, GSH is converted into its oxidized form (GSSG). The ratio of GSH/GSSG is regarded as a sensitive indicator of oxidant stress. ${ }^{52,53}$ A higher ratio of GSH/GSSH indicates a lower level of oxidant stress. The enzyme of GCL is a heterodimer with a large catalytic subunit (GCLc, $\sim 73 \mathrm{kDa}$ ) and a small modifier subunit (GCLm, $\sim 30 \mathrm{kDa}$ ), which are encoded by different genes and dissociated under reducing conditions. ${ }^{54,55}$ ARE is found in the gene promoters of both GCL subunits. ${ }^{56,57}$ The activation of Nrf2 has a critical role in regulation of gene expression of GCL subunits. ${ }^{58}$

Since our earlier results suggested that AGEs inhibited the activation of Nrf2 in HSC, it was, therefore, plausible to explore the impact of AGEs on the expression of GCL and its activity, and further determine the level of GSH and the ratio of GSH/GSSG in HSC. Passaged HSC were treated with AGEs at indicated concentrations for $24 \mathrm{~h}$. Whole-cell extracts were prepared respectively for western blotting analyses of GCL subunits and for GCL activity assays. As shown in Figures 9a and $\mathrm{b}$, AGEs dose-dependently reduced the abundance of GCLc and GCLm, as well as the activity of GCL in HSC. To further explore the impact of AGEs on oxidative stress in HSC, and elucidate the role of curcumin in eliminating the effect of AGEs and in attenuating the AGE-caused oxidative stress, HSC were treated with or without AGEs $(100 \mu \mathrm{g} / \mathrm{ml})$ in the presence of curcumin at indicated doses for $24 \mathrm{~h}$. As shown in Figures $9 \mathrm{c}$ and $\mathrm{d}$, compared with the untreated control (the corresponding first column), AGEs significantly increased cellular oxidative stress demonstrated by reducing the level of cellular GSH (Figure 9c and the ratio of GSH/ GSSG in HSC (Figure 9d) (the corresponding second columns). Curcumin dose-dependently eliminated the inhibitory effect of AGEs. Taken together, these results indicated that AGEs elevated oxidative stress by reducing the abundance of GCL subunits and its enzymatic activity in HSC. The latter was attenuated by curcumin.

\section{The Inhibition of the Activity of GCL Abolished the Role of NAC and Curcumin, and Mimicked the Effects of AGEs on the Divergent Regulation of Gene Expression of RAGE and AGE-R1 in HSC}

Further experiments were necessary to determine whether GSH had a critical role in the AGE-caused divergent regulation of RAGE and AGE-R1 in HSC. Serum-starved HSC were divided into two groups. In one group, cells were stimulated with AGEs $(100 \mu \mathrm{g} / \mathrm{ml})$, or AGEs plus curcumin (Cur) $(20 \mu \mathrm{M})$, or NAC $(5 \mathrm{mM})$, in serum-depleted media for $24 \mathrm{~h}$. Control cells received no treatment. In the other group, cells were pretreated with BSO $(0.25 \mathrm{mM})$ for $1 \mathrm{~h}$ before the addition of AGEs $(100 \mu \mathrm{g} / \mathrm{ml})$, or AGEs plus curcumin $(20 \mu \mathrm{M})$, or NAC $(5 \mathrm{mM})$, in serum-free media for additional $24 \mathrm{~h}$. Total RNA or whole-cell extracts were respectively prepared for real-time PCR or western blotting analyses. As shown in Figure 10, compared with the untreated control (the corresponding first column or well), AGEs, as expected, significantly induced gene expression of RAGE a

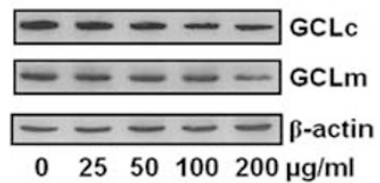

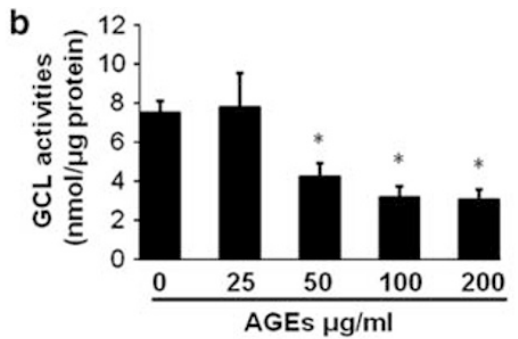
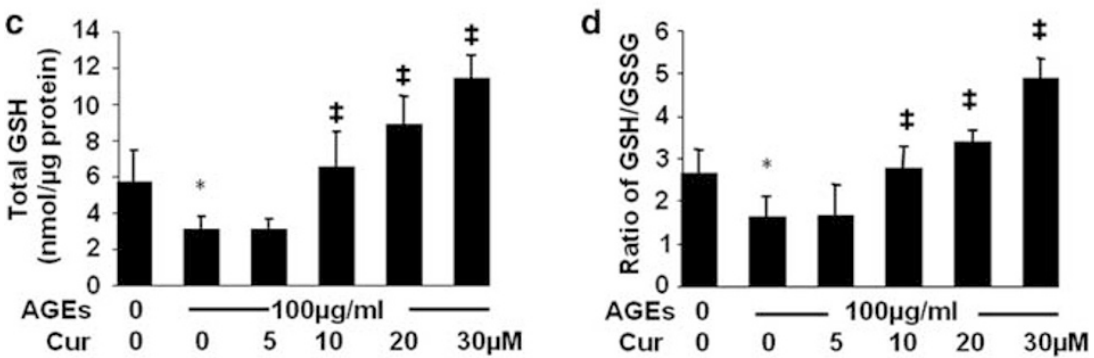

Figure 9 AGEs decreased the abundance of GCL and its activity in HSC, leading to the reduction in the content of cellular GSH, which was eliminated by curcumin. (a, b) Passaged HSC were treated with AGEs at indicated concentrations for $24 \mathrm{~h}$. Whole-cell extracts were prepared respectively for western blotting analyses of GCL subunits (a), or for GCL activity assays (b). $\beta$-Actin was used in western blotting analyses as an invariant control for equal loading. Representatives were presented from three independent experiments. $\mathrm{GCL}$ activities were shown as $\mathrm{nmol} / \mu \mathrm{g}$ protein (mean $\pm \mathrm{s} . \mathrm{d} ., n=3$ ). ${ }^{*} P<0.05$ vs the untreated control cells (the first column). (c, d) HSC were treated with or without AGEs (100 $\mu \mathrm{g} / \mathrm{ml}$ ) in the presence of curcumin (Cur) at indicated doses for $24 \mathrm{~h}$. Cell extracts were prepared for assays. ${ }^{*} P<0.05$ vs the untreated control (the first column); ${ }^{\ddagger} P<0.05$ vs cells treated with AGEs only (the second column). (c) Determination of cellular GSH contents. GSH contents were shown as $\mathrm{nmol} / \mu \mathrm{g}$ protein (mean $\pm \mathrm{s}$.d., $n=3$ ). (d) Determination of the ratio of GSH to GSSG (mean \pm s.d., $n=3$ ). 


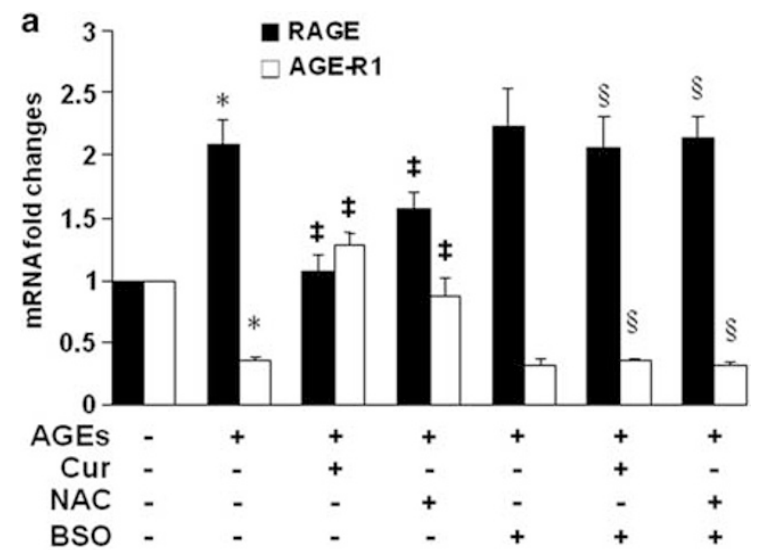

b

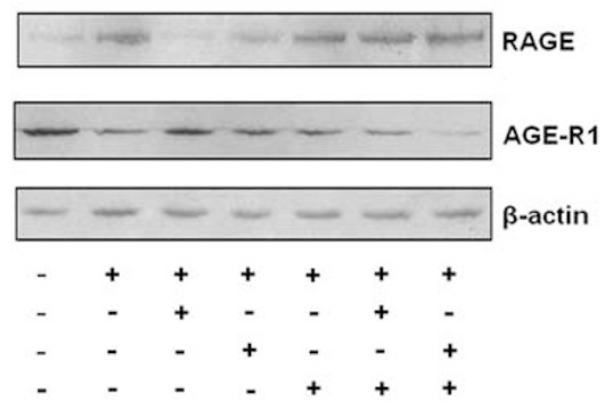

Figure 10 The inhibition of the activity of GCL by BSO abolished the role of NAC and curcumin, and mimicked the effects of AGEs on the divergent regulation of gene expression of RAGE and AGE-R1 in HSC. Serum-starved HSC were divided into two groups. In one group, cells were stimulated with AGEs $(100 \mu \mathrm{g} / \mathrm{ml})$, or AGEs plus curcumin (Cur) $(20 \mu \mathrm{M})$, or NAC $(5 \mathrm{mM})$, in serum-depleted media for $24 \mathrm{~h}$. Control cells received no treatment. In the other group, cells were pretreated with BSO $(0.25 \mathrm{mM})$ for $1 \mathrm{~h}$ before the addition of AGEs $(100 \mu \mathrm{g} / \mathrm{ml})$, or AGEs plus curcumin $(20 \mu \mathrm{M})$, or NAC $(5 \mathrm{mM})$, in serum-free media for additional $24 \mathrm{~h}$. Total RNA or whole-cell extracts were prepared. (a) Real-time PCR analyses of RAGE and AGE-R1 mRNA. Values were expressed as mRNA fold changes (means \pm s.d.) $(n=3) .{ }^{*} P<0.05$ vs the untreated control (the corresponding first column); ${ }^{\ddagger} P<0.05$ vs cells treated with AGEs only (the corresponding second column); ${ }^{\S} P<0.05$ vs cells treated with AGEs plus curcumin, or NAC (the corresponding third or fourth column, respectively). (b) Western blotting analyses of RAGE and AGE-R1. $\beta$-Actin was used as an invariant control for equal loading. Representatives were presented from three independent experiments.

and reduced gene expression of AGE-R1 (the corresponding second columns and wells). Mimicking curcumin (the corresponding third columns and wells), NAC apparently eliminated the effect of AGEs on the divergent regulation of the expression of the two genes (the corresponding fourth columns and wells). It was of interest to observe that the depletion of cellular GSH by the GCL inhibitor BSO abolished the roles of curcumin and NAC in the elimination of the effects of AGEs (the corresponding sixth and seventh columns and wells). Taken together, these results indicated that the inhibition of the activity of GCL and depletion of cellular GSH by BSO abolished the role of NAC and curcumin, and mimicked the effects of AGEs on the divergent regulation of gene expression of RAGE and AGE-R1 in HSC, suggesting the critical role of GSH in the process.

\section{DISCUSSION}

We recently reported that AGEs stimulated HSC activation likely by inducing gene expression of RAGE and suppressing gene expression of AGE-R1, which were abrogated by curcumin. ${ }^{38,39}$ However, the underlying mechanisms remained to be defined. In this report, we demonstrated that AGEs induced gene expression of leptin, activated its signaling and elevated cellular oxidative stress in HSC, leading to the divergent regulation of gene expression of RAGE and AGER1. Curcumin eliminated the effects of AGEs by interrupting leptin signaling, activating Nrf2, and elevating the level of cellular GSH.

AGEs are non-enzymatic adducts of proteins, lipids, and nucleic acids which form in a time-dependent manner in a pro-oxidant environment. ${ }^{5}$ A great deal of AGEs is formed endogenously due to hyperglycemia, hyperlipidemia, and oxidative stress in diabetic patients. ${ }^{59}$ AGEs are accumulated in tissues and circulation during liver fibrogenesis. ${ }^{59}$ In addition, high-fat diets are another major resource of blood AGEs. ${ }^{59}$ It bears indication that AGEs used in this report were generated in vitro system. It remains unknown to what extent these AGEs could represent 'native' AGEs created in vivo system. Although AGEs generated in vivo could be detected in AGEs formed in vitro, the extent of AGE modifications formed in vitro might be unlikely as high as those generated in vivo. ${ }^{60}$

There is an inverse correlation between the dietary AGE content and the ratio of AGE-R1 to RAGE, leading to the increase in oxidative stress, organ damage and the short of life span. ${ }^{61}$ AGEs interact with cells through specific receptors. ${ }^{62}$ Among them, AGE-R1 is a scavenger receptor. ${ }^{11}$ RAGE downregulates cellular defense mechanisms. Studies have implicated that AGEs act as causal factors in the vascular complications of diabetes, ${ }^{61}$ and that RAGE contributes, at least in part, to the development of diabetic complications. ${ }^{5}$ The role of AGEs and RAGE has being implied in the development of NASH-associated hepatic fibrosis. ${ }^{63}$ On the other hand, AGE-R1 acts as a negative regulator of the inflammatory response to AGEs. ${ }^{11}$ Blockade of AGE-RAGE signaling attenuates acetaminophen-induced hepatotoxicity in mice. ${ }^{64}$ It has been suggested that inhibition of AGE formation, blockade of the AGE-RAGE interaction, and suppression of RAGE expression or its downstream pathways may be novel therapeutic strategies for the treatment of AGEcaused complications. ${ }^{65}$ Our results revealed that curcumin showed a novel mechanism to diminish the deleterious effects of AGEs and protect HSC from activation by suppressing gene expression of RAGE and inducing gene expression of AGE-R1.

Our results suggested that the activation of key intermediators $\mathrm{JAK}_{2} / \mathrm{STAT} 3$ and PI3K induced by leptin or AGEs had a critical role in the AGE-caused divergent regulation of gene expression of RAGE and AGE-R1 (Figure 4). However, the rapid activation of $\mathrm{JAK}_{2} / \mathrm{STAT} 3$ and $\mathrm{PI} 3 \mathrm{~K}$ within $30 \mathrm{~min}$ by AGEs in Figures $5 \mathrm{~b}-\mathrm{d}$ was unlikely induced by leptin 
produced by HSC. It has been reported that binding AGEs to RAGE induces sustained post-receptor signaling, including activation of $\mathrm{p} 21^{\text {ras }}$, MAP kinases, and the NF- $\kappa$ B pathway. ${ }^{5}$ Whether AGE-R1 could transduce signals from AGEs remains elusive. It is plausible to assume that the interaction of AGEs and RAGE could rapidly activate $\mathrm{JAK}_{2} / \mathrm{STAT} 3$ and PI3K, which initiates an instant action for the induction of gene expression of leptin and its receptor, and the subsequent activation of leptin signaling, ultimately leading to the divergent regulation of gene expression of RAGE and AGER1. This assumption is supported by our observation. The knockdown of RAGE by RAGE shRNA diminished the stimulant effect of AGEs on the activation of HSC in vitro, suggesting a critical role for the induction of rage expression in the process. ${ }^{39}$ Additional experiments using RAGE shRNA are necessary to further test the assumption, which are being conducted in our laboratory.

The leptin receptor Ob-R is a member of the class I cytokine receptor family. Alternative splicing of $\mathrm{Ob}-\mathrm{R}$ gene results in at least six transcripts designated Ob-Ra through Ob-Rf. ${ }^{66}$ Among them, Ob-Rb contains the longest intracellular domain, which is crucial for leptin signaling. $\mathrm{Ob}-\mathrm{Ra}, \mathrm{Ob}-\mathrm{Rc}$, and Ob-Rd contain only short cytoplasmic domains. Ob-Rd is only found in mice, while Ob-Rf only exists in rats. In human, expression of $\mathrm{Ob}-\mathrm{Ra}, \mathrm{Ob}-\mathrm{Rb}$, and Ob-Rc mRNA has been reported. ${ }^{67}$ We have shown that curcumin dose-dependently reduces the steady-state levels of mRNA of leptin and different isoforms of Ob-Rs, including $\mathrm{Ob}-\mathrm{Ra}, \mathrm{Ob}-\mathrm{Rb}$, and $\mathrm{Ob}-\mathrm{Re}$, in rat HSC in vitro. ${ }^{24}$ Similar results were also observed in mice (data not published). $\mathrm{Ob}-\mathrm{Rb}$ was the target in this report (Figure 1a) by using primers that only hybridized with the region of DNA encoding the intracellular domain. However, we could not exclude the possibility in our report that different receptor isoforms may have different roles in the biology of leptin.

Although underlying mechanisms remain incompletely understood, accumulating evidence has indicated that oxidative stress has critical roles in the activation of HSC..$^{20,68}$ Oxidative stress is a deleterious imbalance between the production and removal of free radicals, including ROS. They are generated from aerobic cells by inflammation and aerobic metabolism. ${ }^{52,53}$ Reducing oxidative stress in mammalian cells is through several antioxidant systems, including enzymes and non-enzymatic molecules. Among them, GSH is the main non-protein thiol. The GSH/GSSG ratio is regarded as a sensitive indicator of oxidant stress. ${ }^{52,53}$ The interaction between AGEs and RAGE generates oxidative stress and subsequently evokes vascular inflammation, thereby having a central role in diabetic complications. ${ }^{69}$ In this study, we demonstrated that, similar to curcumin, the elevation of the level of cellular GSH by NAC eliminated the effect of AGEs on the divergent regulation of RAGE and AGE-R1. These results also highlighted the critical role of elevated oxidative stress in the AGE-caused divergent regulation of the expression of RAGE and AGE-R1 genes, which, in turn, further induced oxidative stress in a manner of positive feedback and accelerated the activation of HSC.

We previously demonstrated that curcumin dose-dependently increased the activity of GCL in passaged HSC by inducing gene expression of both subunits of GCL. ${ }^{34}$ However, the underlying mechanisms were elusive. In this report, we observed that curcumin stimulated the nuclear translocation of Nrf2 and elevated its transcriptional activity in HSC (Figure 7). The transcription factor Nrf2 normally forms a complex with the cytoskeleton-associated protein Keap1 in cytoplasm..$^{49,70}$ Keap1 and Nrf2 constitute a crucial cellular sensor for oxidative stress. ${ }^{49,70} \mathrm{ARE}$ is often found in the promoter of many genes and confers a general transcriptional sensitivity to oxidative stress. ${ }^{50} \mathrm{Nrf} 2$ is essential for the ARE-mediated induction of gene expression of antioxidative stress proteins/enzymes. Our results in this report suggested that in responding to AGEs, the inactivation of Nrf2 resulted in the suppression of gene expression of GCL subunits in HSC. The underlying mechanisms are under investigation. Studies have shown that leptin activates several downstream molecules involved in key pathways related to cell survival such as $\mathrm{JAK}_{2}$, STAT3, PI3K, MAP kinases, AMPactivated protein kinase (AMPK), CDK5, and GSK3 $\beta .{ }^{71}$ Binding AGEs to RAGE induces sustained post-receptor signaling, including activation of $\mathrm{p} 21^{\mathrm{ras}}$, MAP kinases, and the NF- $\kappa$ B pathway. ${ }^{5}$ Our preliminary data suggested that AMPK might be a key regulator in the regulation of Nrf2 activation (data not presented here). Our observations are consistent with prior reports. Phosphorylation of AMPK induces the activation of AMPK, ${ }^{72}$ and in turn, promotes the phosphorylation of Nrf2, which triggers the translocation of Nrf2 from the cytoplasm into the nucleus, leading to its binding to ARE and the induction of expression of target genes. ${ }^{50}$ After computer-aided analyses, no consensus ARE was found in the promoters of rodent RAGE or AGE-R1 genes (data not shown here). It suggested that Nrf2 might be indirectly involved in the divergent regulation of the expression of RAGE and AGE-R1. Although beyond the scope of the current project, additional experiments are ongoing in our laboratory.

On the basis of our observations, a simplified model is proposed to explain the mechanism of AGEs in the divergent regulation of gene expression of RAGE and AGE-R1 in HSC, which is eliminated by curcumin (Figure 11). The interaction of AGEs with RAGE induces gene expressions of leptin and its receptor. The activation of leptin signaling suppresses the activity of Nrf2 and gene expression of GCL and its activity, leading to the reduction in cellular GSH and the elevation of oxidative stress. The latter facilitates the divergent regulation of gene expression of RAGE and AGE-R1. The elevated abundance of RAGE shows a positive feedback mechanism and, in turn, enhances the interaction with AGEs and the subsequent events, collectively leading to the activation of HSC. Curcumin interrupts leptin signaling and blocks the occurrences of the subsequent events, resulting in the 


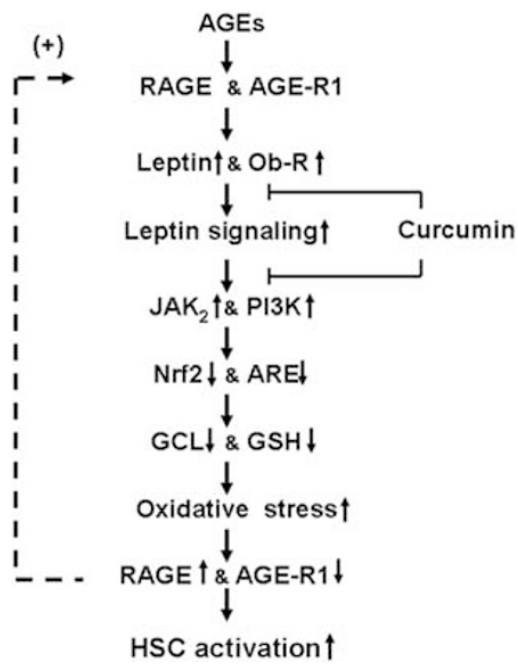

Figure 11 A simplified model of the mechanism of AGEs in the divergent regulation of gene expression of RAGE and AGE-R1 in HSC, which is eliminated by curcumin. The interaction of AGEs with RAGE induces gene expressions of leptin and its receptor, leading to the activation of leptin signaling, including $\mathrm{JAK}_{2}$ and PI3K. The latter suppresses the activity of Nrf2 and gene expression of GCL and its activity, leading to the reduction in cellular GSH and the elevation of oxidative stress. The latter facilitates the divergent regulation of gene expression of RAGE and AGE-R1. The elevated abundance of RAGE shows a positive feedback mechanism and, in turn, enhances its interaction with AGEs and the subsequent events, collectively leading to the activation of HSC. Curcumin interrupts leptin signaling and blocks the occurrences of the subsequent events, resulting in the elimination of the effects of AGEs and the inhibition of HSC activation. ' $\uparrow$ ' or ' $\downarrow$ ' indicates the effects of AGEs. ' $\vdash$ ' represents the inhibitory role of curcumin in the process.

elimination of the effects of AGEs and the inhibition of HSC activation. It bears emphasis that this model does not exclude any other mechanisms involved in the effects of AGEs. In addition, we should not simply conclude that the protective roles of curcumin solely result from these mechanisms studied in this report. No single unequivocal mechanism accounts for all of versatile roles of curcumin against HSC activation. Our results provide novel mechanisms by which curcumin eliminates the effects of AGEs on the divergent regulation of gene expression of RAGE and AGE-R1 in HSC in vitro. Additional experiments are necessary to explore its role in protection of the liver from hepatic fibrogenesis facilitated by hyperglycemia-associated AGEs in vivo.

Supplementary Information accompanies the paper on the Laboratory Investigation website (http://www.laboratoryinvestigation.org)

\section{ACKNOWLEDGMENTS}

The work was supported by RO1 DK 047995 from NIH/NIDDK, the awards from the President Research Fund of Saint Louis University, and from the Liver Center of Saint Louis University to AC.

\section{DISCLOSURE/CONFLICT OF INTEREST}

The authors declare no conflict of interest.
1. Pinzani M. Pathophysiology of non-alcoholic steatohepatitis and basis for treatment. Dig Dis 2011;29:243-248.

2. Ribeireiro T, Swain J, Sarr M, et al. NAFLD and insulin resistance do not increase the risk of postoperative complications among patients undergoing bariatric surgery-a prospective analysis. Obes Surg 2011;21:310-315.

3. Charlton M, Krishnan A, Viker K, et al. Fast food diet mouse: novel small animal model of NASH with ballooning, progressive fibrosis, and high physiological fidelity to the human condition. Am J Physiol Gastrointest Liver Physiol 2011;301:G825-G834.

4. Stefanovic A, Kotur-Stevuljevic J, Spasic S, et al. The influence of obesity on the oxidative stress status and the concentration of leptin in type 2 diabetes mellitus patients. Diabetes Res Clin Pract 2008;79:156-163.

5. Bierhaus A, Humpert PM, Morcos M, et al. Understanding RAGE, the receptor for advanced glycation end products. J Mol Med 2005;83:876-886.

6. Baynes JW. Role of oxidative stress in development of complications in diabetes. Diabetes 1991;40:405-412.

7. Smedsrod B, Melkko J, Araki N, et al. Advanced glycation end products are eliminated by scavenger-receptor-mediated endocytosis in hepatic sinusoidal Kupffer and endothelial cells. Biochem J 1997; 322(Pt 2):567-573.

8. Hyogo $\mathrm{H}$, Yamagishi $\mathrm{S}$, Iwamoto $\mathrm{K}$, et al. Elevated levels of serum advanced glycation end products in patients with non-alcoholic steatohepatitis. J Gastroenterol Hepatol 2007;22:1112-1119.

9. Schmidt AM, Yan SD, Yan SF, et al. The biology of the receptor for advanced glycation end products and its ligands. Biochim Biophys Acta 2000;1498:99-111.

10. Ramasamy R, Yan SF, Schmidt AM. The diverse ligand repertoire of the receptor for advanced glycation endproducts and pathways to the complications of diabetes. Vascul Pharmacol 2012;57:160-167.

11. Lu C, He JC, Cai W, et al. Advanced glycation endproduct (AGE) receptor 1 is a negative regulator of the inflammatory response to AGE in mesangial cells. Proc Natl Acad Sci USA 2004;101:11767-11772.

12. Brett J, Schmidt AM, Yan SD, et al. Survey of the distribution of a newly characterized receptor for advanced glycation end products in tissues. Am J Pathol 1993:143:1699-1712.

13. Tanji N, Markowitz GS, Fu C, et al. Expression of advanced glycation end products and their cellular receptor RAGE in diabetic nephropathy and nondiabetic renal disease. J Am Soc Nephrol 2000;11:1656-1666.

14. Li YM, Mitsuhashi T, Wojciechowicz D, et al. Molecular identity and cellular distribution of advanced glycation endproduct receptors: relationship of p60 to OST-48 and p90 to $80 \mathrm{~K}-\mathrm{H}$ membrane proteins. Proc Natl Acad Sci USA 1996;93:11047-11052.

15. Friedman JM. Modern science versus the stigma of obesity. Nat Med 2004; 10:563-569.

16. Yokaichiya DK, Galembeck E, Torres BB, et al. Insulin and leptin relations in obesity: a multimedia approach. Adv Physiol Educ 2008; 32:231-236.

17. Lee GH, Proenca R, Montez JM, et al. Abnormal splicing of the leptin receptor in diabetic mice. Nature 1996;379:632-635.

18. Leclercq IA, Farrell GC, Schriemer R, et al. Leptin is essential for the hepatic fibrogenic response to chronic liver injury. J Hepatol 2002;37: 206-213.

19. Sakaida I, Jinhua S, Uchida K, et al. Leptin receptor-deficient Zucker $(\mathrm{fa} / \mathrm{fa})$ rat retards the development of pig serum-induced liver fibrosis with Kupffer cell dysfunction. Life Sci 2003;73:2491-2501.

20. Friedman SL. Mechanisms of hepatic fibrogenesis. Gastroenterology 2008:134:1655-1669.

21. Saxena NK, Ikeda K, Rockey DC, et al. Leptin in hepatic fibrosis: evidence for increased collagen production in stellate cells and lean littermates of ob/ob mice. Hepatology 2002;35:762-771.

22. Saxena NK, Saliba G, Floyd JJ, et al. Leptin induces increased alpha2(I) collagen gene expression in cultured rat hepatic stellate cells. J Cell Biochem 2003:89:311-320.

23. Aleffi S, Petrai I, Bertolani C, et al. Upregulation of proinflammatory and proangiogenic cytokines by leptin in human hepatic stellate cells. Hepatology 2005;42:1339-1348.

24. Tang $Y$, Zheng S, Chen A. Curcumin eliminates leptin's effects on hepatic stellate cell activation via interrupting leptin signaling. Endocrinology 2009;150:3011-3020.

25. Wells RG. Liver fibrosis: challenges of the new era. Gastroenterology 2009;136:387-388. 
26. Calamita G, Portincasa P. Present and future therapeutic strategies in non-alcoholic fatty liver disease. Expert Opin Ther Targets 2007;11: 1231-1249.

27. Federico $A$, Niosi $M$, Vecchio Blanco $C D$, et al. Emerging drugs for non-alcoholic fatty liver disease. Expert Opin Emerg Drugs 2008;13: 145-158.

28. O'Connell MA, Rushworth SA. Curcumin: potential for hepatic fibrosis therapy? Br J Pharmacol 2008;153:403-405.

29. Aggarwal BB, Sundaram C, Malani N, et al. Curcumin: the Indian solid gold. Adv Exp Med Biol 2007;595:1-75.

30. $\mathrm{Xu} \mathrm{J}, \mathrm{Fu} \mathrm{Y}, \mathrm{Chen} \mathrm{A}$. Activation of peroxisome proliferator-activated receptor-gamma contributes to the inhibitory effects of curcumin on rat hepatic stellate cell growth. Am J Physiol Gastrointest Liver Physiol 2003;285:G20-G30.

31. Zheng $S$, Chen A. Activation of PPARgamma is required for curcumin to induce apoptosis and to inhibit the expression of extracellular matrix genes in hepatic stellate cells in vitro. Biochem J 2004; 384(Pt 1):149-157.

32. Zheng $\mathrm{S}, \mathrm{Chen} \mathrm{A}$. Curcumin suppresses the expression of extracellular matrix genes in activated hepatic stellate cells by inhibiting gene expression of connective tissue growth factor. Am J Physiol Gastrointest Liver Physiol 2006;290:G883-G893.

33. Zheng $\mathrm{S}$, Chen A. Disruption of transforming growth factor-beta signaling by curcumin induces gene expression of peroxisome proliferator-activated receptor-gamma in rat hepatic stellate cells. Am J Physiol Gastrointest Liver Physiol 2007;292:G113-G123.

34. Zheng S, Yumei $F$, Chen A. De novo synthesis of glutathione is a prerequisite for curcumin to inhibit hepatic stellate cell (HSC) activation. Free Radic Biol Med 2007;43:444-453.

35. Fu Y, Zheng S, Lin J, et al. Curcumin protects the rat liver from $\mathrm{CCl}_{4}$ caused injury and fibrogenesis by attenuating oxidative stress and suppressing inflammation. Mol Pharmacol 2008;73:399-409.

36. Nanji AA, Jokelainen $\mathrm{K}$, Tipoe $\mathrm{GL}$, et al. Curcumin prevents alcoholinduced liver disease in rats by inhibiting the expression of NF-kappa B-dependent genes. Am J Physiol Gastrointest Liver Physiol 2003;284:G321-G327.

37. Park EJ, Jeon $\mathrm{CH}, \mathrm{Ko} \mathrm{G}$, et al. Protective effect of curcumin in rat liver injury induced by carbon tetrachloride. J Pharm Pharmacol 2000;52: 437-440.

38. Lin J, Tang $Y$, Kang $Q$, et al. Curcumin eliminates the inhibitory effect of advanced glycation end-products (AGEs) on gene expression of AGE receptor-1 in hepatic stellate cells in vitro. Lab Invest 2012;92: 827-841.

39. Lin J, Tang $Y$, Kang $Q$, et al. Curcumin inhibits gene expression of receptor for advanced glycation end-products (RAGE) in hepatic stellate cells in vitro by elevating PPARgamma activity and attenuating oxidative stress. Br J Pharmacol 2012;166:2212-2227.

40. Schmittgen TD, Zakrajsek BA, Mills AG, et al. Quantitative reverse transcription-polymerase chain reaction to study mRNA decay: comparison of endpoint and real-time methods. Anal Biochem 2000;285:194-204.

41. Wang XJ, Hayes JD, Wolf CR. Generation of a stable antioxidant response element-driven reporter gene cell line and its use to show redox-dependent activation of nrf2 by cancer chemotherapeutic agents. Cancer Res 2006;66:10983-10994.

42. So HS, Kim HJ, Lee $\mathrm{JH}$, et al. Flunarizine induces Nrf2-mediated transcriptional activation of heme oxygenase- 1 in protection of auditory cells from cisplatin. Cell Death Differ 2006;13:1763-1775

43. Mohr A, Fahrenkamp D, Rinis $\mathrm{N}$, et al. Dominant-negative activity of the STAT3-Y705F mutant depends on the $\mathrm{N}$-terminal domain. Cell Commun Signal 2013:11:83.

44. Tang Y, Chen A. Curcumin protects hepatic stellate cells against leptininduced activation in vitro by accumulating intracellular lipids. Endocrinology 2010;151:4168-4177.

45. Tang $Y$, Chen $A$. Curcumin prevents leptin raising glucose levels in hepatic stellate cells by blocking translocation of glucose transporter-4 and increasing glucokinase. Br J Pharmacol 2010;161:1137-1149.

46. Sterenczak KA, Nolte I, Murua Escobar H. RAGE splicing variants in mammals. Methods Mol Biol 2013;963:265-276.

47. Ahima RS, Osei SY. Leptin signaling. Physiol Behav 2004;81:223-241.

48. Fruhbeck G. Intracellular signalling pathways activated by leptin. Biochem J 2006;393(Pt 1):7-20.
49. Itoh K, Wakabayashi N, Katoh Y, et al. Keap1 represses nuclear activation of antioxidant responsive elements by Nrf2 through binding to the amino-terminal Neh2 domain. Genes Dev 1999;13:76-86.

50. Kobayashi M, Yamamoto M. Molecular mechanisms activating the Nrf2-Keap1 pathway of antioxidant gene regulation. Antioxid Redox Signal 2005;7:385-394.

51. Fraser JA, Kansagra P, Kotecki C, et al. The modifier subunit of Drosophila glutamate-cysteine ligase regulates catalytic activity by covalent and noncovalent interactions and influences glutathione homeostasis in vivo. J Biol Chem 2003;278:46369-46377.

52. Fridovich I. The biology of oxygen radicals. Science 1978;201:875-880.

53. Jones DP. Redox potential of GSH/GSSG couple: assay and biological significance. Methods Enzymol 2002;348:93-112.

54. Seelig GF, Simondsen RP, Meister A. Reversible dissociation of gammaglutamylcysteine synthetase into two subunits. J Biol Chem 1984;259: 9345-9347.

55. Sekura R, Meister A. gamma-Glutamylcysteine synthetase. Further purification, "half of the sites" reactivity, subunits, and specificity. J Biol Chem 1977;252:2599-2605.

56. Mulcahy RT, Wartman MA, Bailey HH, et al. Constitutive and betanaphthoflavone-induced expression of the human gammaglutamylcysteine synthetase heavy subunit gene is regulated by a distal antioxidant response element/TRE sequence. J Biol Chem 1997;272:7445-7454.

57. Moinova HR, Mulcahy RT. An electrophile responsive element (EpRE) regulates beta-naphthoflavone induction of the human gammaglutamylcysteine synthetase regulatory subunit gene. Constitutive expression is mediated by an adjacent AP-1 site. J Biol Chem 1998;273: 14683-14689.

58. Guan SP, Tee W, Ng DS, et al. Andrographolide protects against cigarette smoke-induced oxidative lung injury via augmentation of Nrf2 activity. Br J Pharmacol 2013;168:1707-1718.

59. Sebekova K, Kupcova V, Schinzel R, et al. Markedly elevated levels of plasma advanced glycation end products in patients with liver cirrhosis - amelioration by liver transplantation. J Hepatol 2002; 36:66-71.

60. Makita Z, Vlassara H, Cerami A, et al. Immunochemical detection of advanced glycosylation end products in vivo. J Biol Chem 1992;267: 5133-5138.

61. Vlassara H, Uribarri J, Cai W, et al. Advanced glycation end product homeostasis: exogenous oxidants and innate defenses. Ann NY Acad Sci 2008;1126:46-52.

62. Vlassara H. Palace MR. Diabetes and advanced glycation endproducts. J Intern Med 2002;251:87-101.

63. Lohwasser C, Neureiter D, Popov $Y$, et al. Role of the receptor for advanced glycation end products in hepatic fibrosis. World J Gastroenterol 2009;15:5789-5798.

64. Ekong $\mathrm{U}$, Zeng $\mathrm{S}$, Dun $\mathrm{H}$, et al. Blockade of the receptor for advanced glycation end products attenuates acetaminophen-induced hepatotoxicity in mice. J Gastroenterol Hepatol 2006;21:682-688.

65. Yamagishi S, Nakamura K, Matsui T, et al. Agents that block advanced glycation end product (AGE)-RAGE (receptor for AGEs)-oxidative stress system: a novel therapeutic strategy for diabetic vascular complications. Expert Opin Investig Drugs 2008;17:983-996.

66. Fei $\mathrm{H}$, Okano HJ, Li C, et al. Anatomic localization of alternatively spliced leptin receptors (Ob-R) in mouse brain and other tissues. Proc Natl Acad Sci USA 1997;94:7001-7005.

67. Bernotiene E, Palmer G, Gabay C. The role of leptin in innate and adaptive immune responses. Arthritis Res Ther 2006;8:217.

68. Kisseleva T, Brenner DA. Hepatic stellate cells and the reversal of fibrosis. J Gastroenterol Hepatol 2006;21(Suppl 3):S84-S87.

69. Yamagishi S, Matsui T. Advanced glycation end products, oxidative stress and diabetic nephropathy. Oxid Med Cell Longev 2010;3: 101-108.

70. Bryan HK, Olayanju A, Goldring $\mathrm{CE}$, et al. The Nrf2 cell defence pathway: Keap1-dependent and -independent mechanisms of regulation. Biochem Pharmacol 2013;85:705-717.

71. Folch J, Pedros I, Patraca I, et al. Neuroprotective and anti-ageing role of leptin. J Mol Endocrinol 2012;49:R149-R156.

72. Liu XM, Peyton KJ, Shebib AR, et al. Activation of AMPK stimulates heme oxygenase-1 gene expression and human endothelial cell survival. Am J Physiol Heart Circ Physiol 2011;300:H84-H93. 